\section{Commonwealth English Language Information Centre}

Stating in a written answer in the House of Commons on February 1 that the Government intended to publish the report of the Commonwealth Education Conference in New Delhi as a White Paper as soon as possible, the Minister of Education, Sir David Eccles, indicated that the Conference had decided that a Commonwealth English Language Information Centre should be established in London. This would be responsible for collecting and disseminating information and advice in the best means of teaching English as a second language. Useful surveys were made of the possibilities of further co-operation within the Commonwealth in social education, rural education and the production and distribution of text-books and other books. The Conference agreed that the Commonwealth Education Liaison Committee and Unit should be continued and that they should develop their information functions for member Governments. The British delegation had offered to train and finance experts in teaching English who would be available to fill posts abroad and also to provide courses in the United Kingdom for training technical teachers, more particularly of technicians and eraftsmen. Courses would also be provided in Britain for those concerned with the production of text-books. The offer by the Canadian Government to hold the next Conference in Canada, probably about the middle of 1964, was warmly welcomed.

\section{Employment in Professions Supplementary to Medicine}

Is a debate in the House of Lords on January 24 on shortages in professions supplementary to medicine, Baroness Summerskill directed attention to the grave shortage of qualified dietitians, occupational therapists, physiotherapists and radiographers in the National Health Service. Supported by Lord Geddes, Lord Taylor, Lord Abinger and Lord Stonham, she urged that, while there was no shortage of recruits, salaries and opportunities for promotion were too meagre to prevent a serious shortage, nor was there sufficient inducement for those who left the Service on marriage to return afterwards part time, and Lord Amulree suggested that the demand for such services was likely to increase. In replying for the Government, Lord Newton admitted this increasing demand, and also pointed out that these services were staffed predominantly by women. As such, there was great competition outside the Service for young people possessing similar standards of background, education, character and intelligence, and the position was also adversely affected by the 40 per cent increase in the university undergraduate population since 1953. Nevertheless, Lord Newton gave encouraging figures for increases in physiotherapists, radiographers, dietitians and occupational therapists since 1949 and for recent increases in students in training. Steps had been taken to improve recruitment by increased financial assistance to students, and more effective publicity and memoranda had been issued to hospital authorities advising them on the more effective use of dietitians, radiographers and physiotherapists. As regards salaries, Lord Newton promised to see that the question of income tax on married women's earnings received proper consideration and said that claims for radiographers and physiotherapists were at present under consideration by the appropriate Whitley Council. He denied that there had been a pay-pause for three years: present scales for physiotherapists, occupational therapists and radiographers became effective on January 1, 1961, and for dietitians on March 1, 1961, and none of the four representative bodies had proposed that the Whitley system should be abandoned.

\section{British Government Services in Medical Research}

In a written answer to a question in the House of Commons on January 30 regarding the radiation processing plant on the Slough trading estate, the Parliamentary Secretary for Science, Mr. D. Freeth, stated that the plant would be used to sterilize packaged surgical and pharmaceutical materials to an exceptionally high standard and would incorporate, under licence, patents and other experience derived from the Atomic Energy Authority's pioneer work at Wantage. The Factory and Radioehemical Inspectorate had been consulted about the safety require. ments of the plant, which, when in operation, would be governed by the Ionizing Radiations (Sealed Sources) Regulations. The Minister for Science was satisfied that conformity with these Regulations and precautions would fully safeguard the public. In reply to a subsequent question regarding full-time medical research workers, Mr. Freeth stated that a survey of scientific manpower was now in progress which included an inquiry relating to manpower in medical research, including the National Health Service. On January 1, 1961, the Medical Research Council employed on full-time medical research 189 qualified medical doctors, of whom 19 were engaged on cancer research, 11 on heart disease and 8 on tuberculosis. They were supported by 2,221 other staff, including 500 scientifically qualified, 235 technical officers, 771 technicians and 462 administrative staff, but these figures by no means indicated the Council's total effort in medical research. Medical research was also undertaken in institutions receiving block grants from the Council and by independent scientists who received research grants.

On February 1, replying to a specific question, $\mathrm{Mr}$. Freeth said that the Medical Research Council encouraged and sponsored medical research in every. field. It did not, and in the Government's opinion should not, have a monopoly in deciding what research projects should receive support, but it was responsible for seeing that no line of medical research which is judged to be scientifically worthy suffered from lack of financial support. Its expenditure had more than trebled over the past ten years, and the Minister for Science was satisfied that no really promising lead for medical research by first-class research workers was rejected by the Medical Research Council solely for lack of available funds.

\section{British Technology Index}

THE recent report by the U.S. Office of Technical Services that applied chemists read only about 5 per cent of the available current literature in their immediate field has directed attention to the need for adequate information processing services. While linguistic barriers and the lack of translations obviously form an important part of this problem, it is also a fact that even for English language technical periodicals there is no organized current record of what is published. A significant step towards rectifying this latter situation is taken this month by the appearance of the British Technology Index. Published by the Library Association, this Index will appear monthly with an annual bound cumulative 